\title{
Investigating the effect of social capital sub-dimensions on supply chain collaboration
}

\author{
Vu Dinh Khoa \\ Faculty of Business Management \\ Hanoi University of Industry \\ Hanoi, Vietnam \\ vudinhkhoa@haui.edu.vn
}

\author{
Nguyen Thi Mai Anh \\ Faculty of Business Management \\ Hanoi University of Industry \\ Hanoi, Vietnam \\ nguyenmaianh06@gmail.com \\ nguyenthimaianh@haui.edu.vn
}

\begin{abstract}
The aim of our study is to take a closer look at three dimensions of social capital (SO) and explore the relationship between social capital sub-dimensions and three types of supply chain collaboration. This study provides an in-depth examination of social capital's effect on supply chain collaboration. We developed a comprehensive framework between cognitive, structural and relational capital dimensions and SC collaboration dimensions including information sharing, joint decision making, and benefit/risks sharing. The quantitative method was employed to investigate 249 firms located in Vietnam. The findings of this study provide some important implications for scholars and practitioners to establish and maintain a long-term relationship. The distinguishing between social capital sub-dimensions and collaboration can help managers to design collaborative strategies which will serve for the benefits of the entire supply chain.
\end{abstract}

Index Terms-Social capital, collaboration, Information sharing, decision making, benefit sharing.

\section{IntRoduction}

$\mathrm{T}$ HE COVID-19 epidemic reveals the fragility of worldwide supply chains which arise from raw material scarcity, disruption in manufacturing, and transportation. In order to survive and maintain business, firms need to carefully formulate appropriate collaborative strategies [15].

Supply chain (SC) collaboration is a jointly approved process whereby $\mathrm{SC}$ members can share responsibility, vision, mission, resources, benefits and risks to obtain SC goals [25].

In SC management literature, social capital (SO) is investigated as a critical component of successful collaboration in the SC [31]. Social capital is defined as latent useful resources which are engrained in the relationships between a firm and its allies [30]. A number of researchers indicate that social capital has a prominent place in facilitating SC collaborative actions for example information and resource sharing, mutually profit sharing, joint planning, and innovation [17, 12] . According to previous studies, SO can be divided into three dimensions which are cognitive, structural and relational capital. However, scholars give close attention to the relational facet as the reflection of social capital rather than the two other dimensions. This approach to $\mathrm{SO}$ is no longer suitable in explaining supplier-buyer relationship because those dimensions have different nature and characteristic which may cause the different influence on collaborative activities between suppliers and buyers.

Recently, there are several studies on SC collaboration which investigate the role of social capital as individual sub- dimensions [34,25], or SC collaboration is treated as a progress of generating and exchanging information between suppliers and buyers. Other types of collaboration such as cooperative in decision making process and mutual sharing risk and profits were overlooked. Therefore, it is necessary to investigate the full effects of SO sub-dimensions on SC collaboration in term of three collaborative types.

Responding to this research gap, in this study, we focus on the effects of three SO sub-dimensions on three mutual information sharing, collaborative decision making, and mutual benefits sharing to take a closer look at the difference in the effects of SO dimensions on collaborative activities. The aim of the research is to answer the research questions: "how three dimensions of SO inter-related?" and "how those dimensions affect SC collaboration in term of information sharing, collaborative joint decision, and mutual benefits sharing?" By developing a comprehensive framework between social capital sub-dimensions and SC collaboration, we distinguish the effects of those three social capital dimensions on SC collaboration in term of information sharing, collaborative decision making, and risks and mutual benefits sharing, and explore the inter-relationship among three social capital dimensions.

\section{Literature Review}

\section{A. SC collaboration}

SC collaboration has been defined as the process of cooperation among firms to build close and long-term partnerships, where they integrate resources to meet customer needs better [12]. Some scholars describe SC collaboration as a mutually shared process where firms stake vision, obligation, risks and integrate resources to attain collective goals [25]. In this study, SC collaboration is considered as a partnership process in which independent firms participate in designing strategies and operating SC toward common goals and beneficial outcomes [5]. In order to get better understanding about SC collaboration, we investigate it through three dimensions: sharing information, joint decision, and risks and benefit sharing.

Sharing information: Previous studies indicate that information sharing can improve SC efficiency [20]. Thus, scholars have emphasized the position of knowledge and information in SC relationship. They indicate that SC partners can share relevant market information, accessibility of resources, the position of operation and innovation in an ap- 
propriate time through relational systems [29,26]. Information sharing about market environment, forecasting, planning, customers, and competitors can help firms to face with market and demand uncertainty [2].

Joint decision is demarcated as the process whereby suppliers and buyers cooperate to decide on SC planning and operation to optimize the profit [16,25].

Risks and benefits sharing is the progression of sharing expenses, hazards, and profits among SC members [20]. Sharing risk and benefits would motivate SC partners to engage in a relationship, and exhibit greater commitment and reciprocity among them [4].

\section{B. Social capital and SC collaboration}

Social capital plays a vital role in explaining the nature of cooperation between firms in the SC [3]. [30] describe social capital as valuable resources of firms which are resultant from the network of relationships. Strong social capital between firms can boost collaboration and improve the efficiency of SCs [19]. Social capital involves many facets such as context, network ties, value, and trusting relations. These aspects are represented by three SO sub-dimensions i.e.: structural capital (SSC), relational capital (RSC), and cognitive capital (CSC). Different nature and characteristics of these dimensions can create different effects on SC collaborative [29].

Structural capital mentions the community interactions among parties. It deals with the issue of who you work with and how you work with [30]. Structural capital often contains network configuration and network ties. Network configuration relates to the presence of systems created for one resolution while network ties relate to the strength of linkages and interactions among firms [1].

Rational capital discusses the value that is rooted through relationships [30]. It contains trust, alliance, admiration and reciprocity that are developed during the interactions process [22]. Trust is viewed as a main component of relational capital [27]. Friendship, respect, and reciprocity are built by frequent and repeated interaction and transactions in long-term [29].

Cognitive capital is described as common systems of meaning [27] It is manifested by shared representation, interpretations, and relates to shared common value, culture, goal, and objectives is a prerequisite to focus joint effort from both parties [27].

\section{Proposed Work}

Literature shows that it is challenging to implement SC collaboration, due to the poor social interactions between the members [7,27]. That is why the authors stress on the social capital as a foundation for the successful supplier-buyer relationship. Other authors emphasize the importance of different social capital dimensions on information sharing [14,7], collaborative planning $[16,17]$, suppliers' benefit $[27,4]$. In this paper, we combine all those studies and investigate how the three social capital dimensions affect sharing information, joint decision and risks and benefits sharing and propose the theoretical framework as follow:

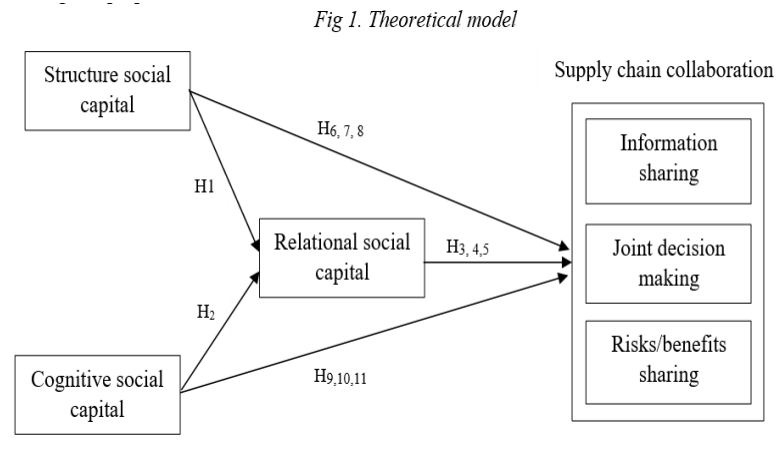

Inter-relationship among different dimensions of social capital.

Previous studies indicates that social interaction can facilitate mutual trust and strengthen the linkage between firms [6]. Proper interactions between suppliers and buyers can facilitate mutual understanding and create trust and trustworthiness [18]. Also, through repeated interactions, supplierbuyer relationships become more concrete which rise the degree of relational capital between them [30,27]. Thus, the hypothesis is proposed:

H1. Structural capital has a positive association with relational capital in SC relationships.

When suppliers and buyers understand and share the same vision, goals and objectives, trust and friendship can be built [11]. It is because common goals and belief may bring and keep firms together, support the agreement in mutual benefits, and reduce opportunistic [29]. Previous studies also suggest that shared common goals and value can reduce misunderstanding and develop mutual trust among firms [6]. Cognitive social capital can be considered as the antecedent of relational capital between suppliers and buyers [6]. Based on the above arguments we propose the hypothesis:

$\mathrm{H} 2$ : Cognitive capital has a positive association with relational capital in SC relationships.

Previous studies indicate that relational capital developed by the social interactions among partners can enable the exchange of knowledge, data, and useful resources [30]. Beside, it also can facilitate communicative efficiency which helps to improve knowledge sharing among partners and reduce the delinquent information asymmetry among SC members [28]. SC literature also indicates that relational social capital facilitates functional integration which is favorable for the process of cooperative decision making and problem-solving [6]. Also, relational capital alters decision process from self-centered individuals into municipal shareholders with mutual goals and objectives. When relational capital exists in the relationship, firms are less concerned that they are abused by their partners, which in turn facilitates the willingness to reciprocate investments [28]. Additionally, due to the ambiguity of transaction, a relationship without relational capital may lead to the unwillingness to share benefits and risks [1]. Therefore the belief of a firm in the good intentions and concern of its partners is an antecedent to mutual benefits and risk-taking. Accordingly, the following hypotheses are suggested:

H3: Relational-capital has a positive association with information sharing

H4: Relational-capital has a positive association with joint decision making

H5: Relational-capital has a positive association with risks/benefit sharing 
Structural capital has been approached as network structural interactions and network ties. Numerous scholars indicate that social interaction facilitates mutual understanding and resource exchange $[36,14]$. Frequent interaction among firms can create opportunities for firms to learn from each other and create the positive collaborative exchange enviroment which can increase the willingness of SC members to joint decision making and create collaborative benefits $[32,28]$. Through communication, firms understand partners better, therefore, they do not feel disinclined to segment important information [13]. Moreover, $\mathrm{Mu}$ et al. (2008) suggests that strong network ties and network configurations can help firms reach consensus on decision making more easily. It also improves the willingness of firms to respond to the problem arising from the relationship [35], facilitates mutual understanding and SC integration, which, in turn, creates the consensus on deciding operational issues. In contrast, lack of structural capital often leads to the anxiety of inadequate distribution of finance and risks, therefore, hinders the collaborative and strategic activities among firms. Accordingly, the following hypotheses are suggested:

H6: Structure capital has a positive relationship with information sharing

H7: Structure capital has a positive association with joint decision making

H8: structure capital has a positive association with risks/benefit sharing

In the SC relationship, communal goals and objectives can force firms to act as one unit to share their information and useful resources. Cognitive social capital which is manifested by shared common goals and value is an applicable factor in amplification the flow of knowledge. It also enables the coordination between suppliers and buyers in exchanging their information and thinking. Moreover, in SC relationships, cognitive social capital can create trust, trustworthiness which reduces conflict and operating disagreement when determining operational issues [21]. It can create co-innovation between suppliers and buyers [27]. When a firm seeks collaboration, cognitive social capital related to common goals and objective can put partners in a more favorable light than others [22]. Therefore, cognitive social capital encourages firms to share profits, cost, and risk. Additionally, Lawson et al. (2008) also argue that when firms share goals and vision, they can work as one firm and integrate to reach the consensus on planning, joint problemsolving, mutual benefits and reduce opportunistic behaviors. Also, shared common goals and objective can reduce opportunism risk in dyadic relationships because it forces firms to behave more accurately [1]. Based on these arguments, we propose the following hypotheses:

H9: Cognitive capital has a positive association with information sharing

H10: Cognitive capital has a positive association with joint decision making

H11: Cognitive capital has a positive association with risks/benefit sharing

\section{Methodology and Result}

\section{A. Measures}

Based on literature review, we originate suitable measures for variables in our questionnaire. Three dimension of social capital are measured by fifteen items collected from previous studies: Structural capital is restrained by five items adopted from Yim and Leem (2013) Nahapiet and Ghoshal (1998) which reflect the interaction among firms in a SC. Cognitive social capital is measured by five items and relational capital is measured by five items. All of the items for these two variables are extracted from [35]. The measurement of three dimensions of SC collaboration are extracted from research of Cao and Zhang (2011).

\section{B. Pretesting and Sampling}

Our study based on the data collected in Vietnam using questionnaire survey method. The target participants of our survey were supply chain managers and team leaders of companies. The questionnaire was floated online using mail. We contacted with Vietnam SC association to get the list of the companies. The list is of 395 suppliers in five sectors (real estate, manufacturing, food, beverage, and pharmaceuticals) located in Hanoi, Hai Phong, Quang Ninh and Bac Ninh province. After having contacted with the participants by phone to explain the purpose of the study, we asked for their cooperation to answer the questionnaire. After that, 388 questionnaires ( 7 representatives refused to take part in the survey) were sent out in the middle of July 2017. After two reminders, 249 participants sent back the questionnaire. The response rate is approximately $64,17 \%$. The final sample size is 249 .

\section{Measurement Model}

SPSS 20 and AMOS 20 were employed to analyze the data. To assess the measurement model, we conduct EFA analysis to screen the variable which has inappropriate commonalities and factor loadings. The result of smaller than 0.5 is accepted. To check the model fit and measurement-scales, we conducted CFA analysis. The results of CFA are presented in table 1 .

Reliability is checked by the criterion of Cronbach's $\alpha$ which is larger than 0.7. From the results, two items of SC performance (SCP7 and SCP8) are omitted to enhance the reliability of this construct. The value for other constructs exceeds 0.7 . The results (table 1) indicate that this methodology achieves solid reliability.

\section{Hypotheses Testing}

The model fit was accessed by multiple indices: GFI exceed 0.8, TLI, CFI surpass 0.9, RMSEA should be between 0.05 to 0.07 . The results show that our model fit is satisfactory.

The hypotheses testing results are shown in table 2. As said by the results, both structural capital and cognitive capital are positively related to relational capital. The correlations of these relationships are $0.114(\mathrm{P}<0.005)$ and 0.375 $(\mathrm{P}<0.01)$ respectively. Thus, $\mathrm{H} 1$ and $\mathrm{H} 2$ are accepted. Structural capital and cognitive capital among SC members can lead to relational capital. This result confirms the inter-relationship between three SO sub-dimensions as indicated in previous studies [24,14,7].

The relationships between relational capital and information sharing, and joint decision, and risks/benefit sharing are confirmed with the correlation of $0.561 \quad(\mathrm{P}<0.001), 0.876$ $(\mathrm{P}<0.001)$ and $0.695(\mathrm{P}<0.001)$ respectively. Thus, H3, H4, 
Table 1: Measurement estimates of major constructs

\begin{tabular}{|c|c|c|c|c|c|c|}
\hline & $\mathrm{FL}$ & $\begin{array}{c}\text { Cronbach } \\
\alpha\end{array}$ & AVE & $\mathrm{CR}$ & MSV & ASV \\
\hline $\begin{array}{l}\text { Cognitive } \\
\text { capital }\end{array}$ & & 0.881 & 0.683 & 0.895 & 0.384 & 0.160 \\
\hline CSC_2 & 0.855 & & & & & \\
\hline CSC_1 & 0.906 & & & & & \\
\hline CSC_3 & 0.832 & & & & & \\
\hline CSC_4 & 0.698 & & & & & \\
\hline $\begin{array}{l}\text { Structure } \\
\text { capital }\end{array}$ & & 0.877 & 0.589 & 0.876 & 0.102 & 0.065 \\
\hline SSC_2 & 0.780 & & & & & \\
\hline SSC_3 & 0.870 & & & & & \\
\hline SSC_5 & 0.815 & & & & & \\
\hline SSC_4 & 0.716 & & & & & \\
\hline SSC_1 & 0.634 & & & & & \\
\hline $\begin{array}{l}\text { Relatio- } \\
\text { nal } \\
\text { capital }\end{array}$ & & 0.788 & 0.434 & 0.789 & 0.423 & 0.234 \\
\hline RSC_3 & 0.586 & & & & & \\
\hline RSC_1 & 0.750 & & & & & \\
\hline RSC_2 & 0.805 & & & & & \\
\hline RSC_5 & 0.526 & & & & & \\
\hline RSC_4 & 0.582 & & & & & \\
\hline $\begin{array}{l}\text { Informa- } \\
\text { tion } \\
\text { sharing } \\
\end{array}$ & & 0.848 & 0.510 & 0.838 & 0.423 & 0.200 \\
\hline IS_4 & 0.740 & & & & & \\
\hline IS_2 & 0.720 & & & & & \\
\hline IS_3 & 0.687 & & & & & \\
\hline IS_1 & 0.636 & & & & & \\
\hline IS_5 & 0.779 & & & & & \\
\hline $\begin{array}{l}\begin{array}{l}\text { Joint } \\
\text { decision } \\
\text { making }\end{array} \\
\end{array}$ & & 0.829 & 0.471 & 0.816 & 0.250 & 0.112 \\
\hline JD_3 & 0.701 & & & & & \\
\hline JD_2 & 0.723 & & & & & \\
\hline JD_4 & 0.709 & & & & & \\
\hline JD_1 & 0.666 & & & & & \\
\hline JD_5 & 0.630 & & & & & \\
\hline $\begin{array}{l}\text { Risk/ } \\
\text { benefits } \\
\text { sharing }\end{array}$ & & 0.844 & 0.555 & 0.858 & 0.123 & 0.049 \\
\hline RS_5 & 0.672 & & & & & \\
\hline RS_3 & 0.604 & & & & & \\
\hline RS_2 & 0.944 & & & & & \\
\hline RS_4 & 0.821 & & & & & \\
\hline RS_1 & 0.626 & & & & & \\
\hline Model fit & $\begin{array}{r}\text { Chi- } \\
\text { square }\end{array}$ & $\begin{array}{r}\text { Chi- } \\
\text { square/df }\end{array}$ & GFI & TLI & CFI & $\begin{array}{c}\text { RMS } \\
\text { EA }\end{array}$ \\
\hline Model & $\begin{array}{r}593.54 \\
4 \\
\end{array}$ & 1.696 & 0.864 & 0.924 & 0.934 & 0.053 \\
\hline
\end{tabular}

and H5 are accepted. This result indicates that relational capital exists in the relationship between suppliers and buyers, it brings firms together to share information and joint operational planning, decision making and reduce the risks of the relationships as well as facilitate investment and benefits sharing among partners. The results also indicate that structural capital has a positive association with information sharing and joint decision making with the correlations of $0.191(\mathrm{P}<0.001), 0.267(\mathrm{P}<0.005)$ respectively. Therefore, H6, H7 is supported. This result implies that structural capital related to social network ties and configuration can lead to mutually sharing information and collaborative decision making among partners. However, the result does not confirm the effect of the structural capital on risks/benefit sharing. The correlations are non-significant. Thus, H8 is not supported.

As shown in table 2, the correlation between cognitive social capital and information sharing is also significant (estimations of $0.313, \mathrm{P}<0.01$ ). Thus, $\mathrm{H} 9$ is supported. Cognitive social capital related to shared common value, culture, objectives, and goals positively affect information sharing between suppliers and buyers. Contrary to our expectation, the relationships between cognitive social capital and joint decision making and cognitive social capital and risks/benefit sharing are not confirmed. Thus, H10 and H11 are rejected. This result indicates that cognitive social capital does not facilitate firms to decide operational issues and other SC problems jointly. It does not lead to the pooling risk and benefit sharing among them.

\begin{tabular}{|c|c|c|c|c|c|}
\hline Hypotheses & $\begin{array}{l}\text { Esti- } \\
\text { mate }\end{array}$ & S.E. & C.R & $\mathrm{P}$ & Decision \\
\hline $\begin{array}{l}\text { Cognitive capital } \rightarrow \\
\text { Relational capital }\end{array}$ & .375 & .056 & 6.743 & $* * *$ & supported \\
\hline $\begin{array}{l}\text { Structural capital } \rightarrow \\
\text { Relational capital }\end{array}$ & .114 & .058 & 1.959 & $*$ & supported \\
\hline $\begin{array}{l}\text { Structural capital } \rightarrow \\
\text { Information sharing }\end{array}$ & .191 & .074 & 2.580 & $* * *$ & supported \\
\hline $\begin{array}{l}\text { Structural capital } \rightarrow \\
\text { Joint decision } \\
\text { making }\end{array}$ & .267 & .086 & 3.090 & $*$ & supported \\
\hline $\begin{array}{l}\text { Structural capital } \rightarrow \\
\text { Risks and benefits } \\
\text { sharing }\end{array}$ & .129 & .088 & 1.464 & Ns & Rejected \\
\hline $\begin{array}{l}\text { Cognitive capital } \rightarrow \\
\text { Information sharing }\end{array}$ & .313 & .074 & 4.219 & $* * *$ & supported \\
\hline $\begin{array}{l}\text { Cognitive capital } \rightarrow \\
\text { Joint decision } \\
\text { making }\end{array}$ & -.273 & .081 & -3.350 & Ns & Rejected \\
\hline $\begin{array}{l}\text { Cognitive capital } \rightarrow \\
\text { Risks and benefits } \\
\text { sharing }\end{array}$ & -.291 & .082 & -3.552 & Ns & Rejected \\
\hline $\begin{array}{l}\text { Relational capital } \rightarrow \\
\text { Information sharing }\end{array}$ & .561 & .131 & 4.268 & $* * *$ & supported \\
\hline $\begin{array}{l}\text { Relational capital } \rightarrow \\
\text { Joint decision } \\
\text { making }\end{array}$ & .876 & .174 & 5.024 & $* * *$ & supported \\
\hline $\begin{array}{l}\text { Relational capital } \rightarrow \\
\text { Risks and benefits } \\
\text { sharing }\end{array}$ & .695 & .197 & 3.521 & $* * *$ & Accepted \\
\hline
\end{tabular}




\section{E. Test of Mediation}

In order to check whether relational capital plays a mediating role in the relationships between the other facets of social capital and collaboration, we use SPSS and follow the instruction of Baron and Kenny (1986). The results shown in Table 3 demonstrate that there are partial mediations in the model. The results indicate that structural capital can lead to information sharing and joint decision making through relational capital and cognitive capital can also encourage information sharing through relational capital.

Table 3: Mediation test

\begin{tabular}{|l|l|l|l|}
\hline Hypothesis & Direct effect & $\begin{array}{l}\text { Indirect } \\
\text { effect }\end{array}$ & Result \\
\hline SSC-> RSC->IS & $.1854 *$ & $.2774^{* * *}$ & $\begin{array}{l}\text { Partial } \\
\text { mediation }\end{array}$ \\
\hline SSC-> RSC->JD & $.2135^{* * *}$ & $.2818^{* * *}$ & $\begin{array}{l}\text { Partial } \\
\text { mediation }\end{array}$ \\
\hline SSC->RSC->RS & $.0699(\mathrm{~ns})$ & $.1261(\mathrm{~ns})$ & No mediation \\
\hline CSC- $>$ RSC->IS & $0.3704 * * *$ & $0.4987 * *$ & $\begin{array}{l}\text { Partial } \\
\text { mediation }\end{array}$ \\
\hline CSC->RSC->JD & $-0.1070(\mathrm{~ns})$ & $0.964(\mathrm{~ns})$ & No mediation \\
& & & No mediation \\
\hline CSC->RSC->RS & $-.1142(\mathrm{~ns})$ & $.0527(\mathrm{~ns})$ & \\
\hline \multicolumn{2}{|l}{} & & \\
\hline
\end{tabular}

\section{Conclusion and Implications}

This study investigates the impact of SO on SC collaboration in a comprehensive framework. Base on the results, we found that structure and cognitive capital positively affect relational social capital. The frequent interaction, strong link and configuration and the similarity in the perception and interpretation of narratives among individual actor can help to build trust, friendships and mutual understanding among SC members [30]. Moreover, the results also reveal that dissimilar dimensions of social capital have dissimilar effects on collaborative activities such as sharing information, joint decision, and risks and benefit sharing.

\section{A. Academic contributions}

Our research provides some contributions to the area of SC management. Firstly, the outcomes provide a nuanced knowledge about the effect of SO on SC collaboration. This study is an insight into how structural, cognitive, and relational social capital affect sharing information, joint decision, and risks and benefits sharing. Second, this is the first study to combine three types of social capital and three subdimensions of SC collaboration into one framework. Earlier studies investigating the relationship between SO and SC collaboration often focus on knowledge and information sharing among firms and skip two other types of collaborative activities (joint decision and risks and benefits sharing, which play essential roles in the successful and effective SC collaboration). By focusing on SC collaboration in the implementation process, this study also provides a different approach in studying the role of SO on collaboration in SCs. Lastly, our study also provides empirical sign to support the literature on the inter-relationship between social capital dimensions. Furthermore, while investigating the inter-relationship of social capital dimensions, the results reveal the mediating effect of relational capital on the relationships between the two other dimensions capital and collaboration. The findings of this study help broaden the understanding about the mechanism for building relational capital and achieving fruitful collaboration though social capital.

\section{B. Managerial contributions}

COVID-19 is a record and extraordinary event affecting the global SCs. This is truly a novel challenge for SC managers. Ensuring collaboration in the $\mathrm{SC}$ is a demanding concern. By study the relationship between SO and SC collaboration, our study gives some suggestions for the firms. First, by improving the level of interaction, network ties, trust, friendship, belief, and collaborative culture, both parties can collaborate more efficiently and therefore can improve the outcome of collaboration and avoid wasting time on pointless operational adjustments. More importantly, they can collaborate to operate SC management without worrying about opportunistic behaviors and the uncertainty of the relationship. SC collaboration based on the foundation of social capital can also reduce the reluctant of firms to share information and resources and make effort to provide quality goods and services to the customers. Besides, the distinguishing between three dimensions of social capital and collaboration can also help managers to realize the advantages of different collaborative activities and the mechanism to create that benefit. Managers need to understand that their business success is dependent on success of collaboration with SC partners, so that understanding and communicating effectively with partners can help firms to strengthen and endure the collaborative relationship.

Finally, the outcomes of our study recommend that policymakers should take actions to facilitate social capital among SC members. From the social capital standpoint, they can create some policies to improve the quality of SC relationships and create some motivations to inspire collaborative activities.

\section{REFERENCES}

[1] Alghababsheh, M. \& Gallear, D. J. J. O. B. E. 2021. Socially sustainable SC management and suppliers' social performance: The role of social capital. 173, 855-875.

[2] Baah, C., Opoku Agyeman, D., Acquah, I. S. K., Agyabeng-Mensah, Y., Afum, E., Issau, K., Ofori, D. \& Faibil, D. 2021. Effect of information sharing in SCs: understanding the roles of SC visibility, agility, collaboration on SC performance. Benchmarking: An International Journal, ahead-of-print.

[3] Baron, R. M. \& Kenny, D. A. 1986. The moderator-mediator variable distinction in social psychological research: Conceptual, strategic, and statistical considerations. Journal of personality and social psychology, 51, 1173

[4] Blonska, A., Storey, C., Rozemeijer, F., Wetzels, M. \& De Ruyter, K. 2013. Decomposing the effect of supplier development on relationship benefits: The role of relational capital. Industrial Marketing Management, 42, 1295-1306.

[5] Cao, M. \& Zhang, Q. 2011. SC collaboration: Impact on collaborative advantage and firm performance. Journal of Operations Management, 29, 163-180.

[6] Carey, S., Lawson, B. \& Krause, D. R. 2011. Social capital configuration, legal bonds and performance in buyer-supplier relationships. Journal of Operations Management, 29, 277-288.

[7] Chang-Hun, L. \& Byoung-Chun, H. 2018. The impact of buyersupplier relationships' social capital on bi-directional information sharing in the SC. Journal of Business \& Industrial Marketing, 33, 325-336.

[8] Chin, W. W., Marcolin, B. L. \& Newsted, P. R. 2003. A Partial Least Squares Latent Variable Modeling Approach for Measuring 
Interaction Effects: Results from a Monte Carlo Simulation Study and an Electronic-Mail Emotion/Adoption Study. Information Systems Research, 14, 189-217.

[9] Colicchia, C., Creazza, A., Noè, C. \& Strozzi, F. J. S. C. M. A. I. J. 2019. Information sharing in SCs: a review of risks and opportunities using the systematic literature network analysis (SLNA).

[10] Corgnet, B., Espín, A. M., Hernán-González, R., Kujal, P. \& Rassenti, S. 2016. To trust, or not to trust: Cognitive reflection in trust games. Journal of Behavioral and Experimental Economics, 64, 20-27.

[11] Crescenzi, R., Nathan, M. \& Rodríguez-Pose, A. 2016. Do inventors talk to strangers? On proximity and collaborative knowledge creation. Research Policy, 45, 177-194.

[12] Do Canto, N. R., Bossle, M. B., Vieira, L. M. \& De Barcellos, M. D 2021. SC collaboration for sustainability: a qualitative investigation of food SCs in Brazil. Management of Environmental Quality: An International Journal, 32, 1210-1232.

[13] Ha, B. C., Park, Y. K. \& Cho, S. 2011. Suppliers' affective trust and trust in competency in buyers: Its effect on collaboration and logistics efficiency. International Journal of Operations \& Production Management, 31, 56-77.

[14] Handoko, I., Bresnen, M. \& Nugroho, Y. 2018. Knowledge exchange and social capital in SCs. International Journal of Operations \& Production Management, 38, 90-108.

[15] Kumar, G. 2021. Collaboration between SC partners: when does it matter? Evidence from collaborative profiles. Journal of Business \& Industrial Marketing, 36, 1042-1057.

[16] Kumar, G., Banerjee, R. N., Meena, P. L. \& Ganguly, K. K. 2017. Joint planning and problem solving roles in SC collaboration. IIMB Management Review, 29, 45-57.

[17] Lang, T. \& Ramírez, R. 2017. Building new social capital with scenario planning. Technological Forecasting and Social Change, 124, 51-65.

[18] Lawson, B., Tyler, B. B. \& Cousins, P. D. 2008. Antecedents and consequences of social capital on buyer performance improvement. Journal of Operations Management, 26, 446-460.

[19] Li, Y., Ye, F. \& Sheu, C. 2014. Social capital, information sharing and performance: Evidence from China. International Journal of Operations \& Production Management, 34, 1440-1462.

[20] Liao, S.-H., Hu, D.-C. \& Ding, L.-W. 2017. Assessing the influence of SC collaboration value innovation, SC capability and competitive advantage in Taiwan's networking communication industry International Journal of Production Economics, 191, 143-153.

[21] Mai Anh, N. T., Hui, L. \& Khoa, V. D. 2018. Emerging Economies of Southeast Asia: Achieving and increasing radical innovations through collaborating with buyers and suppliers by fostering trust: the Case of Viet Nam. Journal of Business-to-Business Marketing, 25, 357-372.
[22] Morgan, R. \& Hunt, S. 1994. The Commitment-Trust Theory of Relationship Marketing, Journal of Marketing.

[23] Mu, J., Peng, G. \& Love, E. 2008. Interfirm networks, social capital, and knowledge flow. Journal of Knowledge Management, 12, 86-100.

[24] Nahapiet, J. \& Ghoshal, S. 1998. Social Capital, Intellectual Capital, and the Organizational Advantage. Academy of Management Review, 23, 242-266.

[25] Nguyen, M. A. T., Lei, H., Vu, K. D. \& Le, P. B. 2019. The role of cognitive proximity on SC collaboration for radical and incremental innovation: a study of a transition economy. Journal of Business \& Industrial Marketing, 34, 591-604.

[26] Raweewan, M., Ferrell Jr, W. G. J. C. \& Engineering, I. 2018. Information sharing in SC collaboration. 126, 269-281.

[27] Sukoco, B. M., Hardi, H. \& Qomariyah, A. 2018. Social capital, relational learning, and performance of suppliers. Asia Pacific Journal of Marketing and Logistics, 30, 417-437.

[28] Thi Mai Anh, N. 2019. Relational capital and SC collaboration for radical and incremental innovation. Asia Pacific Journal of Marketing and Logistics, 31, 1076-1094.

[29] Thi Mai Anh, N., Hui, L., Khoa Vu, D. \& Mehmood, S. 2019. Relational capital and SC collaboration for radical and incremental innovation: An empirical study in China. Asia Pacific Journal of Marketing and Logistics, 31, 1076-1094.

[30] Tsai, W. P. \& Ghoshal, S. 1998. Social capital and value creation: The role of intrafirm networks. Academy of Management Journal, 41, 464476

[31] Villena, V. H., Revilla, E. \& Choi, T. Y. 2011. The dark side of buyer-supplier relationships: A social capital perspective. Journal of Operations Management, 29, 561-576.

[32] Wang, Y. 2016. Investigating dynamic capabilities of family businesses in China: a social capital perspective. Journal of Small Business and Enterprise Development, 23, 1057-1080.

[33] Wu, L. \& Chiu, M.-L. J. I. J. O. I. M. 2018. Examining SC collaboration with determinants and performance impact: Social capital, justice, and technology use perspectives. 39, 5-19.

[34] Yang, z., Lin, y. J. S. P. \& consumption 2020. The effects of SC collaboration on green innovation performance: An interpretive structural modeling analysis. 23, 1-10.

[35] Yao, L., Yu, Z. \& Songyue, Z. 2016. Social capital, portfolio management capability and exploratory innovation: evidence from China. Journal of Business \& Industrial Marketing, 31, 794-807.

[36] Yim, B. \& Leem, B. 2013. The effect of the SC social capital. Industrial Management \& Data Systems, 113, 324-349. 